\title{
Chitosan Nanoparticles with Encapsulated Natural and UF-Purified Annatto and Saffron for the Preparation of UV Protective Cosmetic Emulsions
}

\author{
Sonia Ntohogian ${ }^{1}$, Viktoria Gavriliadou ${ }^{1}$, Evi Christodoulou ${ }^{1}$, Stavroula Nanaki ${ }^{1}$, \\ Smaro Lykidou ${ }^{1}$, Panagiotis Naidis ${ }^{1}$, Lily Mischopoulou ${ }^{1}$, Panagiotis Barmpalexis ${ }^{2}$ (D), \\ Nikolaos Nikolaidis ${ }^{1, *}$ and Dimitrios N. Bikiaris ${ }^{1, *}$ (iD \\ 1 Laboratory of Chemistry and Technology of Polymers and Dyes, Department of Chemistry, \\ Aristotle University of Thessaloniki, 54124 Thessaloniki, Greece; sonita_nt@hotmail.gr (S.N.); \\ victoria.vgche@gmail.com (V.G.); evicius@gmail.com (E.C.); sgnanaki@chem.auth.gr (S.N.); \\ slykidou@chem.auth.gr (S.L.); pan-naidis@hotmail.com (P.N.); magoo-mm@hotmail.com (L.M.) \\ 2 Department of Pharmaceutical Technology, School of Pharmacy, Aristotle University of Thessaloniki, \\ 54124 Thessaloniki, Greece; pbarmp@pharm.auth.gr \\ * Correspondence: nfnikola@chem.auth.gr (N.N.); dbic@chem.auth.gr (D.N.B.); \\ Tel.: +30-2310-997812 (N.N. \& D.N.B.)
}

Academic Editor: Jyh-Ping Chen

Received: 20 July 2018; Accepted: 20 August 2018; Published: 22 August 2018

\begin{abstract}
The aim of the present work is to evaluate the preparation of sunscreen emulsions based on chitosan (CS) nanoparticles with annatto, ultrafiltrated (UF) annatto, saffron, and ultrafiltrated saffron. Ionic gelation was used for the preparation of chitosan nanoparticles, while their morphological characteristics and physicochemical properties were evaluated via Fourier transform infrared (FTIR) spectroscopy, X-ray diffraction (XRD) analysis, scanning electron microscopy (SEM), and dynamic light scattering (DLS). Results showed that the prepared nanoparticles ranged from 150 to $~ 500 \mathrm{~nm}$ and had a spherical or irregular shape. In the case of annatto and UF annatto, due to the formation of H-bonds, the sunscreen agents were amorphously dispersed within CS nanoparticles, while in the case of saffron and UF saffron, crystalline dispersion was observed. All encapsulated materials had good thermal stability as well as color stability. In a further step, sunscreen emulsions were prepared based on the formed CS-sunscreen nanoparticles and evaluated for their stability in terms of $\mathrm{pH}$ and viscosity, along with their ultraviolet (UV) radiation protection ability in terms of sun protection factor (SPF). All prepared emulsions showed low cytotoxicity and good storage stability for up to 90 days, while minimum sunscreen protection was observed with SPF values varying from 2.15 to 4.85 .
\end{abstract}

Keywords: chitosan; nanoparticles; sunscreen; annatto; saffron; sun protection factor

\section{Introduction}

Today, it is well documented that many of the adverse effects resulting from the exposure of skin to solar radiation are mainly caused by ultraviolet (UV) radiation from solar rays. Specifically, although UV-C radiation (100-290 nm) is totally filtered out by the earth's ozone layer, UV-A (320-400 nm) and UV-B (290-320 nm) radiations are responsible for several skin pathologies such as sunburns, cutaneous degeneration, photosensitivity, phototoxicity, photoaging, immunosuppression, and skin cancer [1,2]. In order to prevent these adverse reactions, sunscreens that contain filter substances with strong protective efficacy against UV radiation are widely used. 
Sun protection creams, lotions, oils, emulsions, and textiles are common choices of cosmetic/wear products used for sun protection, while materials of either physical or chemical nature are commonly selected as sun protecting (sunscreen) agents [3]. These agents act by absorbing/scattering or attenuating the solar UV radiation, respectively [4]. The efficacy of a sunscreen agent or the resultant sun protection product is usually expressed in terms of sun protection factor (SPF), where generally, a higher SPF value corresponds to more effective protection [5-7]. Several problems related to sunscreen products currently available on the market include high opacity with unacceptable appearance on the skin, erythema, edema, and irritation, among others [3]. In order to overcome these drawbacks, formulators have turned their attention to nanotechnology by designing formulas in which appropriate carriers work as vehicles for carrying nanosized sunscreen agents (such as zinc and titanium dioxide), by which more effective and cosmetically acceptable sunscreen products are prepared $[3,8,9]$. One such highly effective biocompatible material, used as a nanocarrier in the production of sun protection products, is chitosan (CS) [10,11].

CS is a polysaccharide of $N$-acetyl-D-glucosamine and D-glucosamine consisting of polymeric $(1 \rightarrow 4)$-linked 2 -amino-2-deoxy- $\beta$-D-glucopyranose units produced by the deacetylation of chitin [12-14]. CS is a biocompatible, nontoxic, and biodegradable material and shows good mucoadhesive and membrane-permeability-enhancing properties [15-19]. Due to several advantages, CS-based nanoparticles have been extensively evaluated as absorption enhancers (for drugs, peptides, and proteins) and as carriers in various drug delivery systems for oral, ocular, gene delivery, etc. [14,19-27]. There are several methods available for CS nanoparticle preparation including ionotropic gelation, microemulsification, emulsification solvent diffusion, and polyelectrolyte complexing [28]. Out of these, ionotropic gelation offers many advantages, such as simple and mild preparation without the use of organic solvents or high shear forces [13,28-32].

Nowadays, it is widely recognized that among the reasons for the development of severe skin damages due to sun exposure is also the production of free radicals [33]. Recently, it was demonstrated that $50 \%$ of free radicals are produced by solar radiation in the visible (VIS) and infrared (IR) spectral region [34]. Therefore, for ultimate skin protection, new concepts need to emerge that can effectively block the radiation of the earth's complete solar spectrum (UV, VIS, and IR spectral regions). Such approaches may utilize the application of pigments and antioxidants [34], where, in the former case, the sunscreen agent acts as micromirror in the human skin, reflecting the sunlight not only in the UV but also in the VIS/IR spectral regions [35,36]. Such naturally occurring sunscreen agents that can combine both pigment and antioxidant properties may come from plant extracts such as green tea polyphenols, silymarin from milk thistle, proanthocyanidins from grape seeds, etc. $[37,38]$. Annatto, which comes from the family of Bixaceae (Achiote family), grows to a height of 2-5 $\mathrm{m}$ and is well distributed in Karnataka, Andhra Pradesh, Assam, Tamil Nadu, and Orissa (India). The dye coming from annatto is basically a red-orange pigment known as bixin and norbixin (carotenoids) and is extracted from the seed coat, which is inside a prickly heart-shaped pod, and is used in food, cosmetic, and soap industries as pigment [39]. Additionally, annatto's carotenoids are considered as powerful antioxidant compounds [40]. Saffron is the dried red/yellow stigmas of a flower scientifically identified as Crocus sativus L, which is cultivated in Iran and some other countries such as India, Spain, and Greece. Pharmacological studies have been revealed that saffron extracts or its constituents have antitumor, hypolipidemic, radical scavenging, antinociceptive, anti-inflammatory, anticonvulsant, antidepressant, and antioxidant properties [41-45]. Therefore, due to the combination of pigment and antioxidant properties, several attempts have been made in order to prepare sunscreen formulations based on annatto or saffron $[38,39,46,47]$.

Hence, the aim of the present study is to prepare new CS-based nanoparticles loaded with annatto or saffron and to evaluate their applicability in the preparation of new sunscreen products. For this reason, CS nanoparticles loaded with natural and ultrafiltrated (UF) annatto or saffron, prepared by ionotropic gelation, will be evaluated, while the SPF and stability of a new sunscreen emulsion will be accessed. 


\section{Results and Discussion}

\subsection{CS-Based Nanoparticles}

Generally, during ionotropic gelation, the formation of CS nanoparticles depends mainly on the ionic interaction of CS with tripolyphosphate (TPP), which eventually leads to the reduction of CS aqueous solubility. The effect of various ratios between CS and TPP on the size and particle distribution of CS nanoparticles was extensively studied in previous works [14]. Results indicated that good nanoparticles with a relatively low polydispersity index may result from CS:TPP ratios varying from 2:1 up to 5:1. Hence, in the present study, CS nanoparticles were prepared at a 2:1 CS-to-TPP ratio. In order to evaluate the particle size and morphology of the prepared nanoparticles, SEM was used. Figure 1 shows the obtained dynamic light scattering (DLS) data of the blank CS nanoparticles and the prepared CS-loaded annatto, UF annatto, saffron, and UF saffron nanoparticles. For the blank sample, nanoparticles with a mean particle size of $250 \mu \mathrm{m}$ were produced (Table 1), which was verified from DLS measurements and SEM micrographs.

From the obtained SEM micrographs (data not shown), it is seen that both annatto (or UF annatto) and saffron (or UF saffron) nanoparticle size and morphology did not differ compared to the blank CS nanoparticles, indicating that the addition of the sunscreen protective agents did not affect the nanoparticle preparation method. In regards to annatto and UF-annatto-CS nanoparticles, the particle size ranged from $\sim 170$ to $\sim 450 \mathrm{~nm}$ and had a mixed spherical and irregular shape, while the use of physical and UF annatto did not show any substantial differences regarding the size and shape of the resultant nanoparticles. Additionally, the varying annatto concentration $(20-60 \% w / w)$ did not alter the morphological characteristics of the obtained particles. Furthermore, in the case of saffron and UF-saffron-CS-prepared nanoparticles, particle size varied from 150 to 500 nm, while the shape of the obtained nanoparticles was similar to that of annatto (or UF annatto)-CS nanoparticles. In order to have a better idea regarding the particle size distribution of the prepared nanoparticles, DLS measurements were conducted and the results are presented in Figure 1.
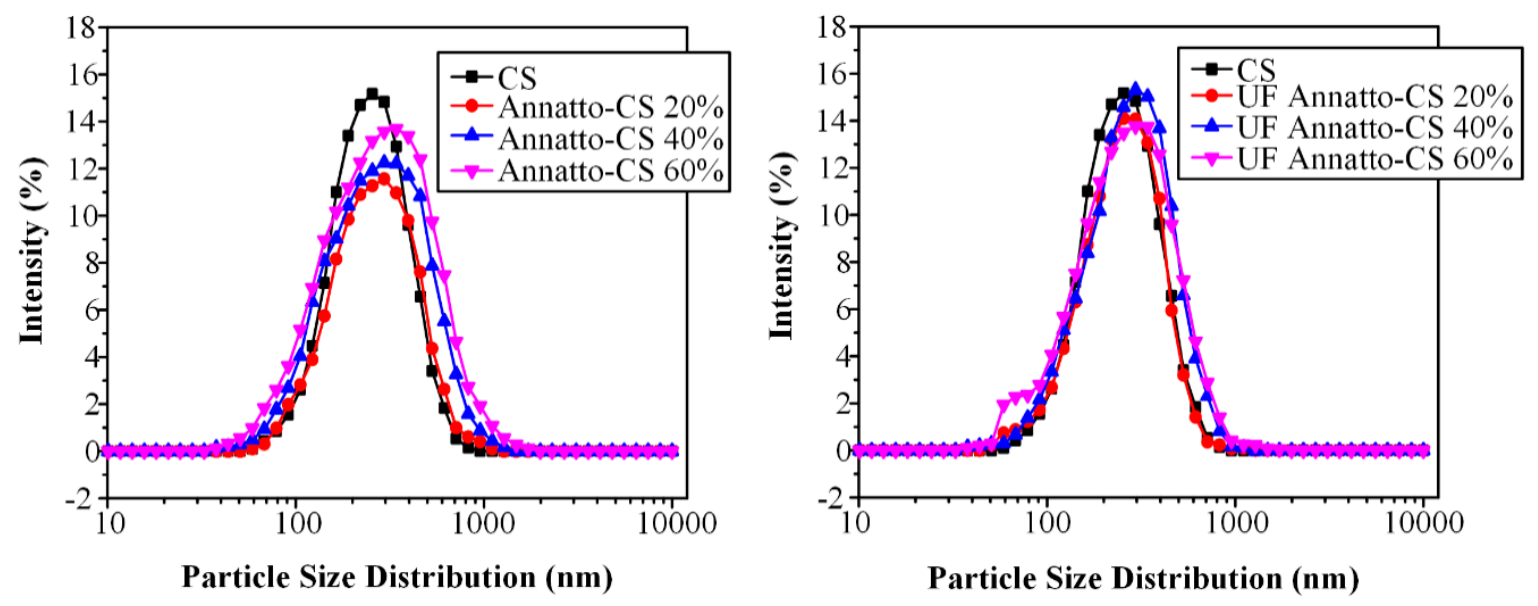

Figure 1. Particle size distribution measured by dynamic light scattering (DLS) of chitosan (CS)-loaded nanoparticles with annatto and ultrafiltrated (UF) annatto.

As can be seen, in all nanoparticles, there is a broad size distribution varying from about 40 to 1000-1100 nm. When annatto was encapsulated in CS nanoparticles, the D(50) value is slightly increased compared to nanoparticles with neat CS (from 250 to 287-340 nm), while nanoparticle size increases with increasing annatto's concentration (Table 1). This is probably because annatto has no reactive amino group that could ionically interact with TPP and thus annatto has a hindering effect to form ionically crosslinked gels. A similar trend was also observed when UF annatto was encapsulated 
in CS nanoparticles, where slightly lower $\mathrm{D}(50)$ values where observed compared to nanoparticles with annatto (probably due to UF annatto's higher solubility). The zeta potential of chitosan nanoparticles is about $36 \pm 3 \mathrm{mV}$, which is in agreement with the reported values for ionically crosslinked CS nanoparticles with TPP [48]. In encapsulated CS/annatto nanoparticles, the zeta potential remains positive, while their values were slightly increased compared to neat CS nanoparticles (Table 1). Similar results were also recorded for saffron and UF-saffron-CS-based nanoparticles (Table 1).

Table 1. Nanoparticles particle size $(\mathrm{D}(50))$, zeta-potential, yield, sunscreen agent loading, and entrapment efficiency results.

\begin{tabular}{cccccc}
\hline Sample & $\mathbf{D}(\mathbf{5 0 )}(\boldsymbol{\mu m})$ & Zeta Potential $(\mathbf{m V})$ & Yield (\%) & Loading (\%) & Entrapment Efficiency (\%) \\
\hline Blank & $250 \pm 7$ & $36 \pm 3$ & - & - & - \\
Annatto-CS & & & & & \\
$20 \mathrm{wt} \%$ & $287 \pm 5$ & $34 \pm 3$ & 70.83 & 15.62 & 66.40 \\
$40 \mathrm{wt} \%$ & $310 \pm 8$ & $41 \pm 3$ & 65.80 & 29.62 & 68.25 \\
$60 \mathrm{wt} \%$ & $340 \pm 11$ & $46 \pm 3$ & 61.25 & 41.17 & 67.25 \\
UF-annatto-CS & & & & & 45.01 \\
$20 \mathrm{wt} \%$ & $263 \pm 9$ & $35 \pm 3$ & 47.80 & 15.69 & 62.06 \\
$40 \mathrm{wt} \%$ & $284 \pm 10$ & $40 \pm 3$ & 46.34 & 38.27 & 71.54 \\
$60 \mathrm{wt} \%$ & $303 \pm 8$ & $47 \pm 3$ & 55.07 & 48.71 & 21.25 \\
Saffron-CS & $321 \pm 6$ & $42 \pm 3$ & 67.75 & 20.52 & 37.50 \\
UF-saffron-CS & $298 \pm 8$ & $43 \pm 3$ & 83.75 & 25.61 & \\
\hline
\end{tabular}

In a further step, FTIR analysis was used in order to identify any possible interactions taking place between the sunscreen agents and CS, since any kind of physicochemical interaction will automatically lead to frequency shifts or splitting in the observed absorption peaks compared to the peaks of the neat compounds. Figure 2 shows the FTIR spectra of the prepared annatto and UF-annatto-CS nanoparticles. In regards to pure CS, several characteristic absorbance peaks were identified at: (1) $3400 \mathrm{~cm}^{-1}$, where the characteristic peak of the hydroxyl group $\mathrm{m}(\mathrm{OH})$ is recorded along with the overlapped peak of N-H stretch at $3278 \mathrm{~cm}^{-1}$; at (2) 1657 and $1594 \mathrm{~cm}^{-1}$, where the characteristic peaks of amide I and amide II bands are depicted, respectively; at (3) $1322 \mathrm{~cm}^{-1}$, where the characteristic peak of C-N stretch is recorded; and at (4) $1079 \mathrm{~cm}^{-1}$, where the characteristic peak of $\mathrm{C}-\mathrm{O}$ stretch is recorded. In the case of CS-TPP nanoparticles, the FTIR peaks corresponding to the amino group's absorption is shifted to 1640 and $1530 \mathrm{~cm}^{-1}$, indicating that these groups are probably interacting with TPP by creating ionic bonds. Additionally, a shift in the hydroxyl group band is recorded with a maximum at $3416 \mathrm{~cm}^{-1}$, indicating possible formation of H-bonds. In the case of annatto and UF annatto, the FTIR spectra display a broadband at $3400 \mathrm{~cm}^{-1}$ (ascribed to the stretching vibration of the $-\mathrm{OH}$ group), at 2920 and $2855 \mathrm{~cm}^{-1}$ (associated with the stretching vibrations of the hydrocarbon skeleton), and at 1690,1603 , and $1149 \mathrm{~cm}^{-1}$ (assigned to the stretching vibration of the $C=O$ group, the conjugated $C=C$ group, and the $-\mathrm{CO}$ of the carboxylic acid group).

All these absorption peaks can be ascribed to the carotenoid compounds of the annatto (bixin and norbixin). Additionally, no significant spectral differences were observed between the annatto and the UF annatto, indicating the UF process did not alter the chemical characteristics of the compound. In regards to annatto-CS nanoparticles, FTIR analysis showed that in the region of the hydroxyl group stretching (3600-3000 $\mathrm{cm}^{-1}$ ), a broader peak is observed compared to the neat compounds, indicating that probably some $\mathrm{H}$-bonds are taking place between the hydroxyl or amino groups of CS with the carboxyl groups of annatto or UF annatto. Additionally, analysis showed no significant spectral differences between the nanoparticles containing different amounts of annatto or UF annatto (20\%, $40 \%$, and $60 \%$ ), indicating that the same interactions (H-bonds) with CS are occurring independently of annatto (or UF annatto) concentration, while small differences in the intensity of the observed peaks may be attributed to the different encapsulation percentage of annatto (or UF annatto). 

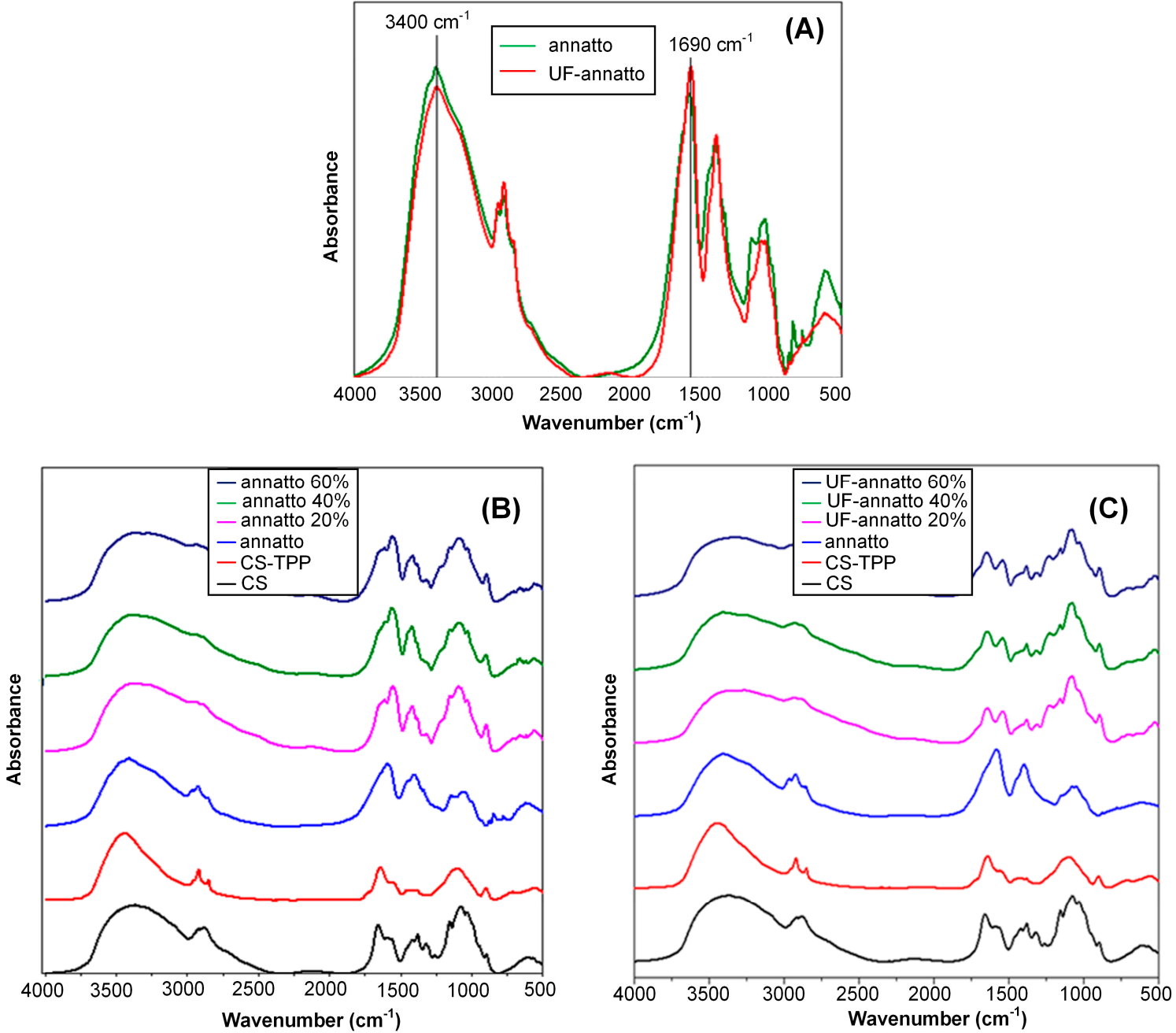

Figure 2. FTIR spectra of: (A) annatto and UF annatto; (B) neat CS, CS/tripolyphosphate (TPP) and annatto-CS nanoparticles; and (C) UF-annatto-CS nanoparticles.

Figure 3 shows the FTIR spectra of the prepared saffron-CS nanoparticles. Analysis of the saffron (or UF saffron) FTIR spectra did not show any significant differences between the two compounds, indicating that the UF process followed, although results in a more purified compound do not alter the chemical structure of saffron, while the spectra of both compounds showed several characteristic peaks [49].

Specifically, the band at $\sim 3300 \mathrm{~cm}^{-1}$ is due to the stretching vibration of $\mathrm{O}-\mathrm{H}$, which indicates the presence of alcoholic groups. The two peaks in the region of $3000-2750 \mathrm{~cm}^{-1}$ correspond to $\mathrm{C}-\mathrm{H}$ stretching vibration, which is indicative of the aldehyde group found in volatile components of saffron such as safranal. The $\mathrm{C}=\mathrm{O}$ stretching vibration was found at $\sim 1700 \mathrm{~cm}^{-1}$ in the spectra for saffron and UF saffron, while the presence of characteristic bands in the region of $1300-1220 \mathrm{~cm}^{-1}$ are due to stretching vibration of ester $(\mathrm{O}=\mathrm{C}-\mathrm{O})$ groups, which are due to constituents of saffron such as dimethylcrocetin as well as alcohol groups found in the carbohydrate moiety of crocin esters and picrocrocin. The strong peak at $1100-1000 \mathrm{~cm}^{-1}$ is due to the stretching vibration mode of conjugated $\mathrm{C}-\mathrm{C}$ bonds of the central carotenoid chain, which is characteristic for carotenoids such as crocetin esters. This peak might also be a characteristic of pyranose moiety, with multichain peaks related to the sequential arrangement of hydroxyl groups. In regards to the saffron-CS nanoparticles' FTIR spectra, significant differences were observed at $3400-3000 \mathrm{~cm}^{-1}$ (region where characteristic peaks of both $\mathrm{O}-\mathrm{H}$ and $\mathrm{N}-\mathrm{H}$ groups are observed) and at $1594 \mathrm{~cm}^{-1}$, where the characteristic peak of amide II for CS 
shifts to lower wavenumbers, indicating the presence of significant interactions (probably H-bonds) between the two compounds. Similar differences were also observed in the case of UF-saffron-CS nanoparticles (data not shown).
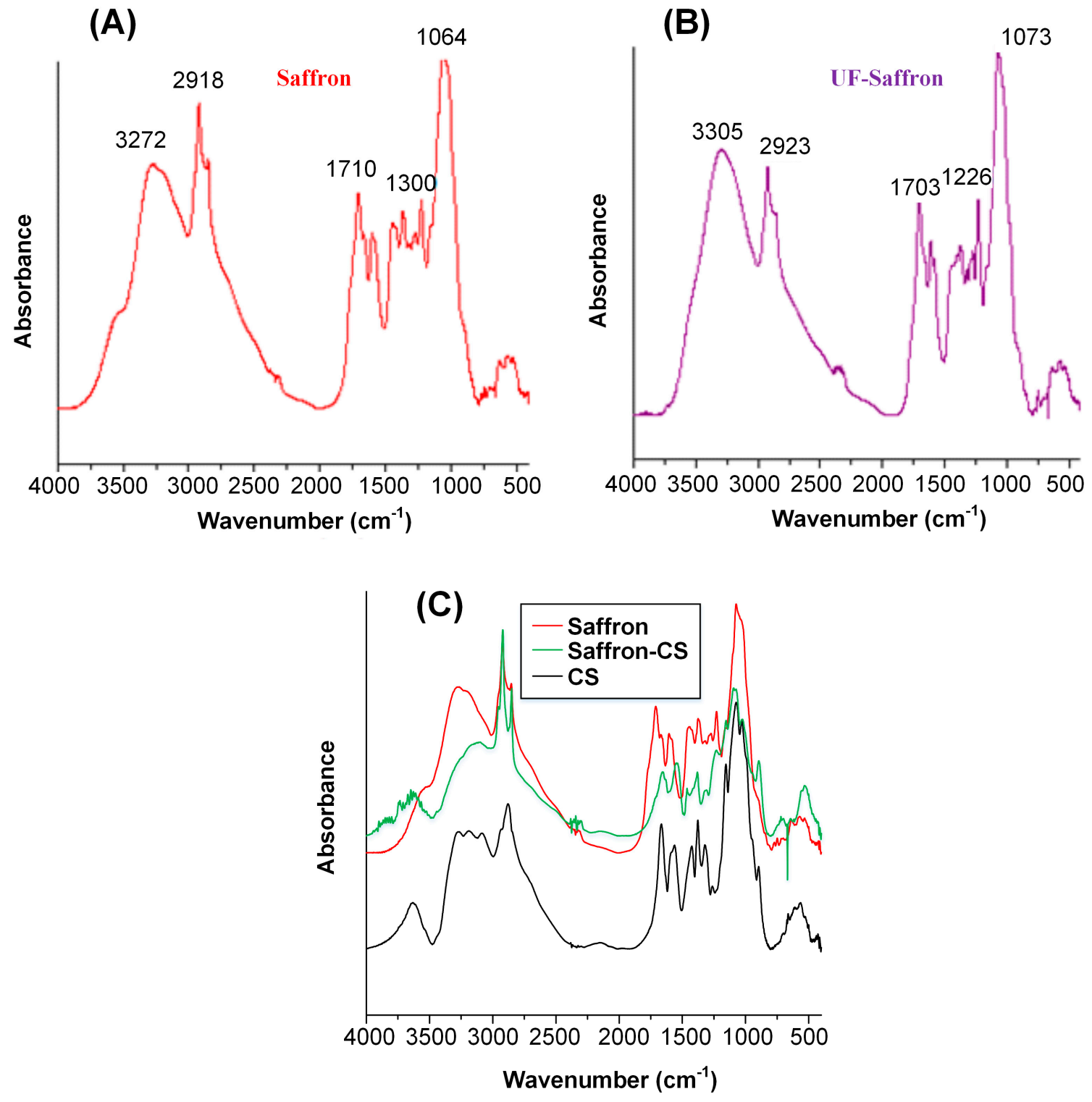

Figure 3. FTIR spectra of saffron (A), UF saffron (B), and saffron-CS nanoparticles (C).

In a further step, in order to identify the physical state of the tested naturally occurring sunscreen agents within the CS nanoparticle system, wide angle X-ray diffractometry was used. Figure 4 shows the XRD diffractograms of the neat components and the prepared nanoparticles. In regards to neat CS, XRD analysis showed two broad peaks at $2 \theta=11^{\circ}$ and mainly at $21^{\circ}$, verifying the semicrystalline nature of the polymer. When CS-TPP nanoparticles have been prepared, these are completely amorphous, since only a broad halo was recorded. Annatto showed high crystallinity, with XRD peaks recorded at $2 \theta$ of $27^{\circ}, 29^{\circ}, 34^{\circ}, 36^{\circ}$, and $40^{\circ}$, while no differences were observed between the XRD patterns of annatto and UF annatto, indicating that no polymeric transition occurs during the UF process. On the other hand, both neat saffron and UF saffron showed similar XRD patterns, with an amorphous halo at $\sim 20^{\circ}$ indicating that the sunscreen agents are amorphous. 

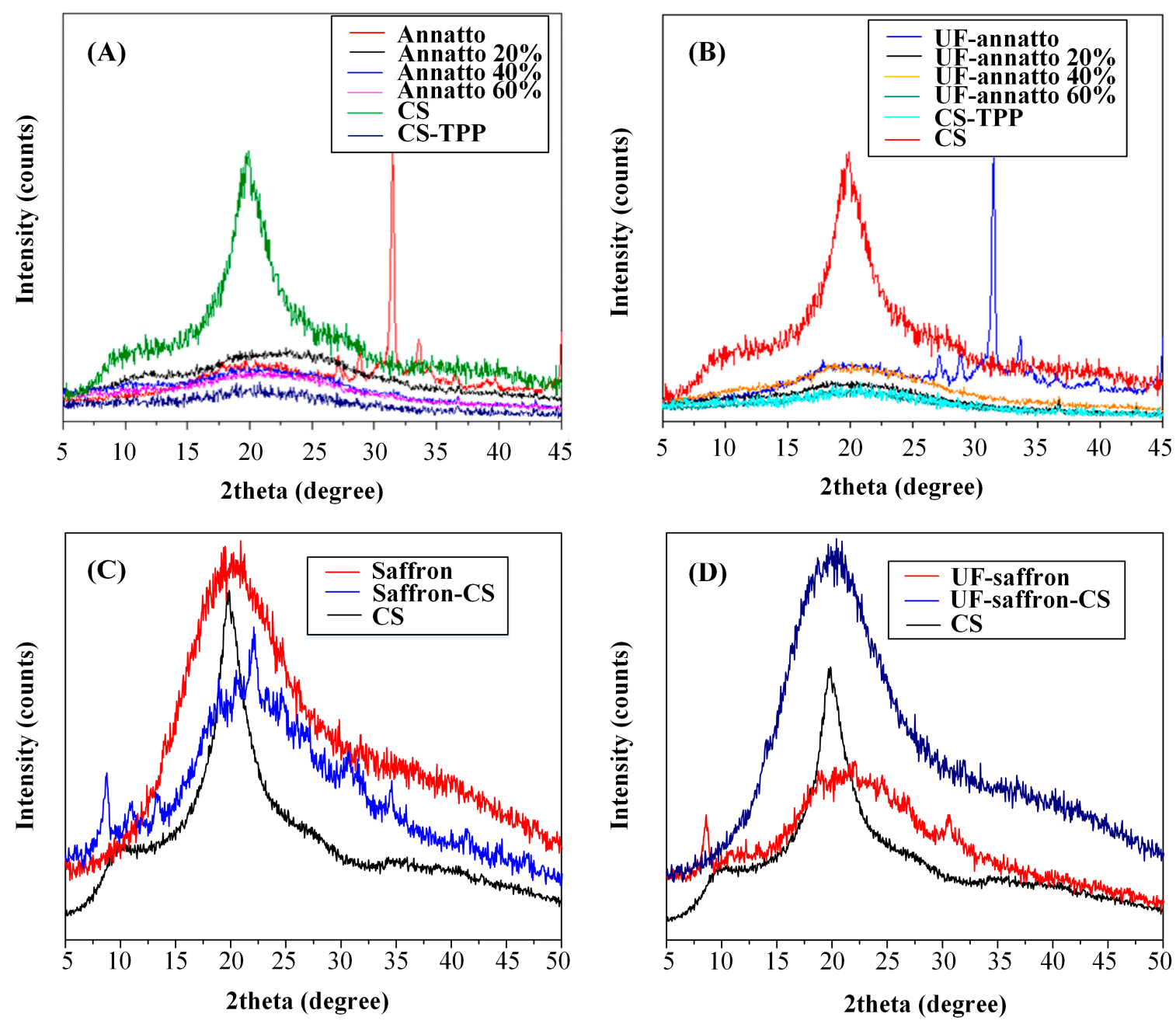

Figure 4. XRD diffractograms of: (A) CS, CS-TPP, annatto and annatto-CS nanoparticles; (B) UF-annatto and UF-annatto-CS nanoparticles; (C) saffron and saffron-CS nanoparticles; (D) UF-saffron and UF-saffron-CS nanoparticles.

In regards to annatto-CS and UF-annatto-CS nanoparticles, XRD analysis showed that all prepared systems were amorphous, as no annatto- or UF-annatto-related XRD peaks were recorded. Additionally, increasing annatto (or UF annatto) concentration did not result in any significant change of the XRD patterns, expect in the reduction of the intensity of the broad peak of CS at $21^{\circ}$ (due to lower CS concentration). The observed amorphization of annatto and UF annatto in the prepared CS nanoparticles may be attributed to the interactions observed by FTIR analysis (H-bonds). In the case of saffron and UF-saffron-CS nanoparticles, XRD analysis showed the presence of several small crystalline peaks at approximately $2 \theta$ of $8^{\circ}, 11^{\circ}, 18^{\circ}, 22.5^{\circ}$, and $30^{\circ}$ along with a characteristic amorphous halo. Since saffron is completely amorphous, these small peaks indicate that CS was transformed during nanoencapsulation into another crystalline form, which is in good agreement with the literature [50].

In regards to nanoparticle yields, UF-saffron-CS nanoparticles showed the highest yield, with a value of $83.75 \%$, followed by annatto-CS nanoparticles, with a yield of $70.83 \%$, while the lowest yield was obtained for UF-annatto-CS, with a value of $46.34 \%$ (Table 1). Additionally, in the case of annatto-CS nanoparticles, increasing amounts of annatto led to decreasing nanoparticle yield values, while the use of UF annatto led to opposite results, with increasing yields at higher sunscreen concentrations. In the case of sunscreen loadings, results from Table 1 show that increasing annatto and UF annatto concentrations led to increasing loading percentages. In saffron and UF saffron 
nanoparticles, the results showed a lower loading presentence, perhaps due to the higher solubility of saffron compared with annatto. Finally, increased entrapment efficiency values were observed in the case of most of the annatto and UF-annatto-CS nanoparticles, while low entrapment was observed in the case of saffron and UF-saffron-CS nanoparticles (Table 1).

The thermal stability of the prepared materials was evaluated via thermogravimetric analysis (TGA). As can be seen form Figure 5, chitosan has two main decomposition steps (Figure 5a). The first, corresponding to adsorbed moisture, takes place between ambient temperature and 120 ${ }^{\circ} \mathrm{C}$ [51]. The second takes place at much higher temperatures, with maximum mass loss at $320^{\circ} \mathrm{C}$, corresponding to the decomposition of polysaccharide macromolecular chains. Saffron and UF saffron have similar decomposition behaviour since both are natural products. There is a gradually small mass loss till $200{ }^{\circ} \mathrm{C}$ due to the absorbed water and, after that, the main decomposition takes place with a maximum decomposition at $250{ }^{\circ} \mathrm{C}$ (Figure 5b). In the case of encapsulated CS/saffron and CS/UF saffron, as expected, the thermal behaviour lies between the neat materials. At initial stages, absorbed water is volatised gradually till $200{ }^{\circ} \mathrm{C}$, and after that point, the main decomposition takes place, which lies between that of saffron and CS (closer to saffron).
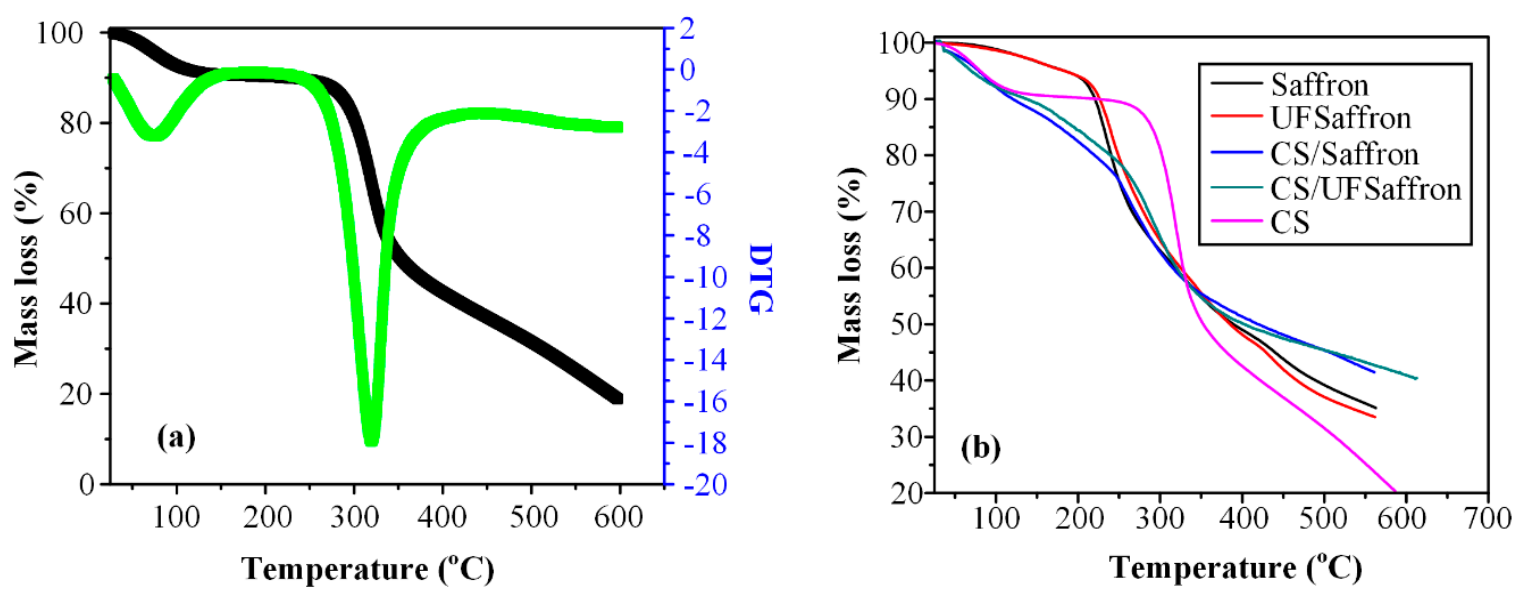

Figure 5. Thermogravimetric analysis (TGA) curves of neat CS (a) and the encapsulated materials on CS containing $40 \mathrm{wt} \%$ saffron or UF saffron (b).

Even though chitosan is extensively used as a drug carrier due to its low cytotoxicity, saffron and annatto cytotoxicity were also tested in order to ensure that they are appropriate for the proposed applications. In Figure 6, the HUVEC cells' viability is presented after incubation for $24 \mathrm{~h}$ of neat CS, saffron, annatto, and their nanoencapsulated additives, in comparison with a well-established biocompatible polymer (poly(lactic acid), PLA), which is extensively used in biomedical applications [52,53].

From the calculated data, it can be seen that neat materials (CS, saffron, and annatto) have in all studied concentrations similar cytotoxicity to PLA. This was expected since all of these materials are naturally occurring with many applications in food and pharmaceutical industries, especially CS. Similar behaviour was also observed for the encapsulated annatto and saffron additives into chitosan nanoparticles. In all concentrations, their cytotoxicity was comparable to that of neat materials. Thus, it can be said that these materials can be used in biomedical applications. 


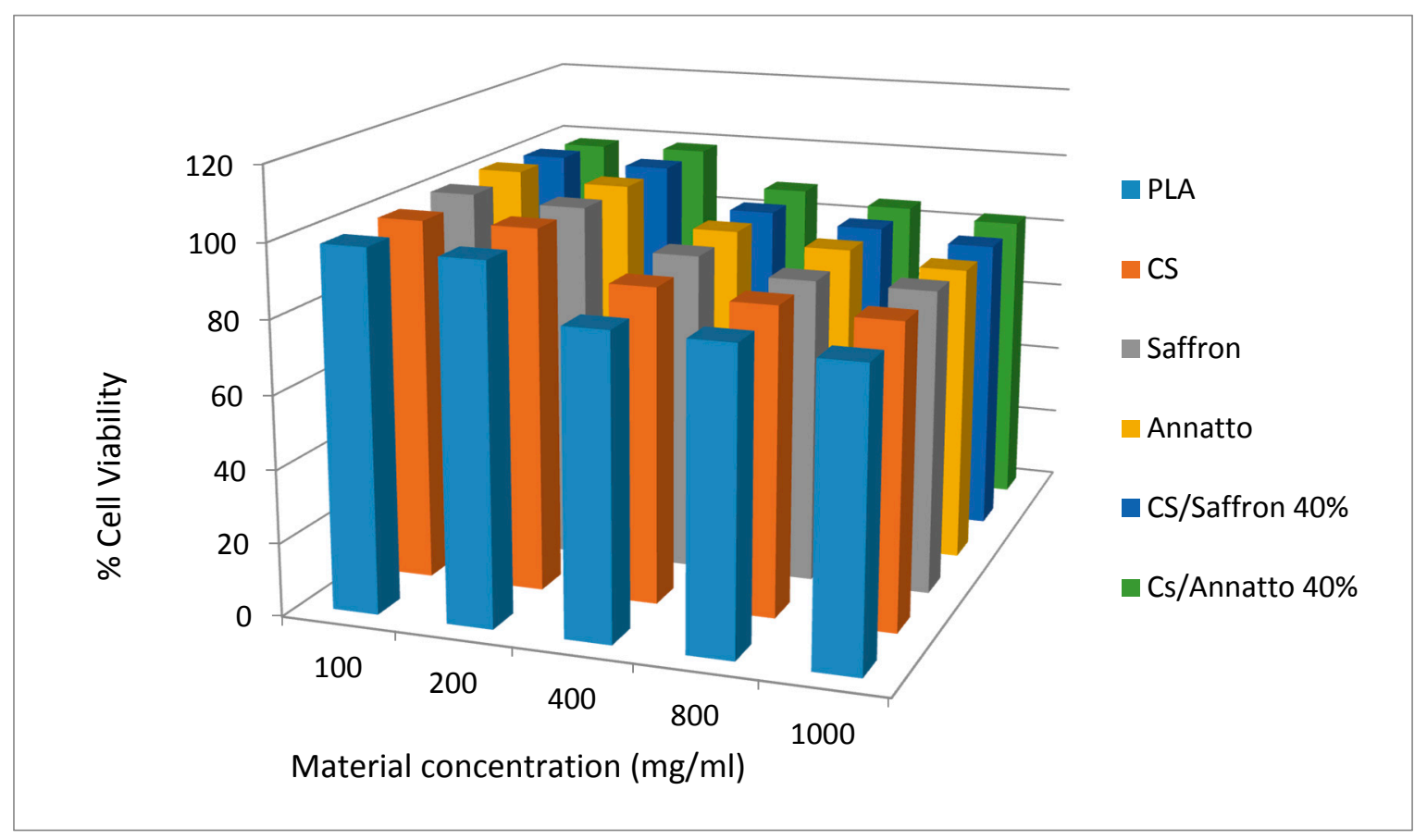

Figure 6. HUVEC cells viability after incubation for $24 \mathrm{~h}$ for different concentrations of CS, saffron, annatto, and their encapsulated nanopreparations, compared to biocompatible PLA polyester.

\subsection{Sunscreen Emulsions}

For the preparation of the sunscreen emulsions, the followed procedure resulted in the formation of cream-like emulsions that had a yellowish color in the case of annatto and UF annatto and a yellow to orange color in the case of saffron and UF saffron preparations. Additionally, increasing amounts of annatto and UF annatto resulted in an increase of color intensity, as expected, while blank (with no sunscreen protecting agent) emulsions, prepared also for comparison, had a white to creamy-white color.

\subsubsection{Emulsion Stability Results}

In regards to emulsion stability, monitoring the $\mathrm{pH}$ value during storage is a crucial aspect, since $\mathrm{pH}$ changes indicate the occurrence of possible chemical reactions [54,55]. Given that the human skin $\mathrm{pH}$ value ranges from 4.5 to 6.0 , products intended for topical use should have a $\mathrm{pH}$ value that is within that range [56]. In the present study, all prepared formulations had a $\mathrm{pH}$ value well within this range ( $\mathrm{pH}$ value ranged from 5.44 to 5.88), indicating that they can be used as topical sunscreen emulsions.

Figure 7 shows the $\mathrm{pH}$ values during storage stability for all formulations. In regards to annattoand UF-annatto-based formulations, all emulsions had a slightly lower $\mathrm{pH}$ value compared to the blank emulsion, which, however, was within the acceptable $\mathrm{pH}$ range, and good $\mathrm{pH}$ stability was observed up to 90 days in all cases. Additionally, good $\mathrm{pH}$ emulsion stability was also observed for the saffron and UF saffron emulsions independently of the use of CS and the preparation of nanoparticles, indicating that the incorporation of the sunscreen agents within a CS-based nanoparticle system does not affect the $\mathrm{pH}$ stability of the resultant emulsion. 

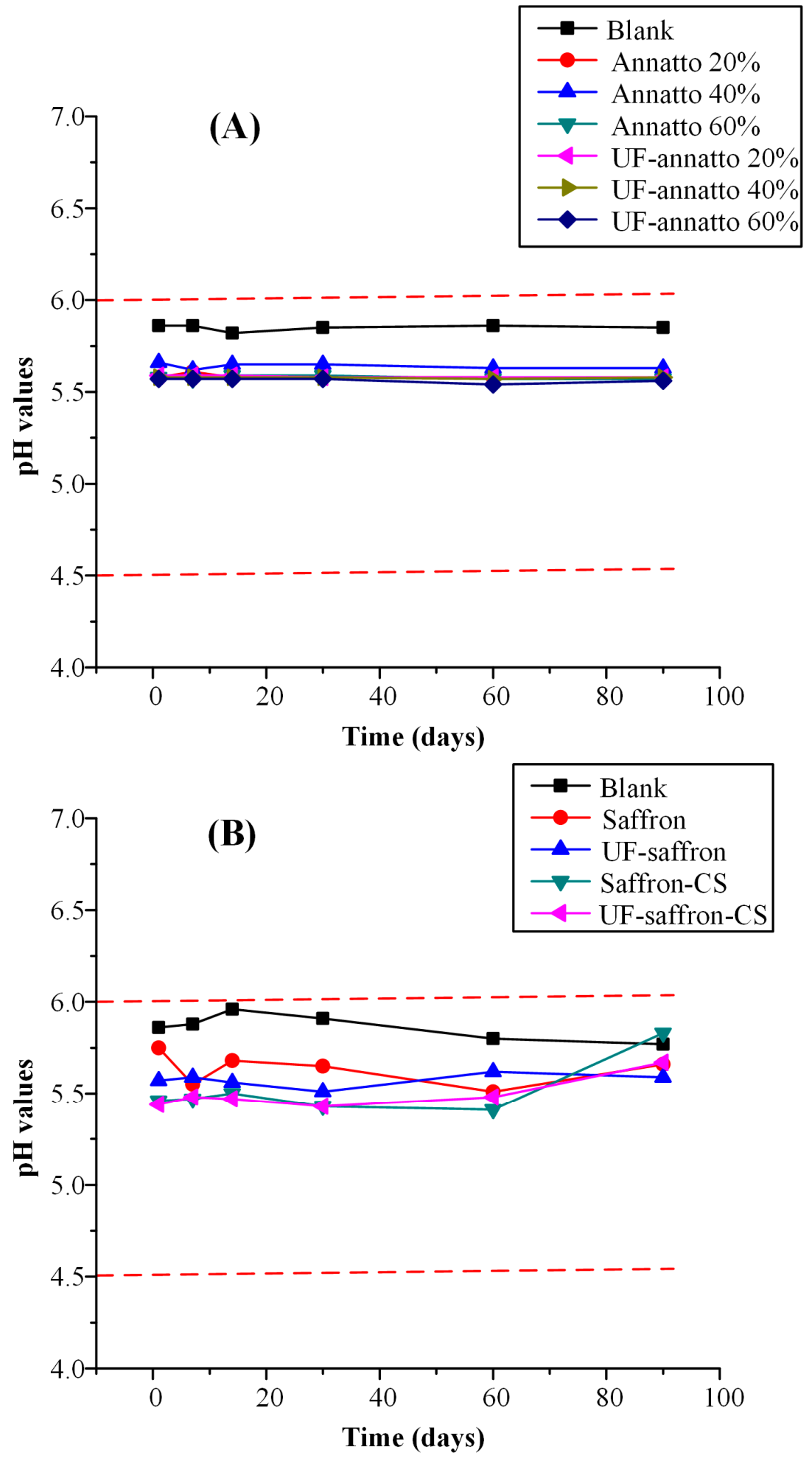

Figure 7. $\mathrm{pH}$ values of prepared sunscreen emulsions during storage stability studies for annatto/UF-annatto (A) and saffron/UF-saffron (B) samples. Red dashed lines depict the acceptable $\mathrm{pH}$ range of 4.5-6.0.

Another important factor related to emulsion stability is the changes that may occur in emulsion's viscosity profile. Changes in viscosity during storage may result in several defects, not only in regards to aesthetic appearance (liquefaction) but also in the fundamental aspects of the final product, such as 
the sun-protective ability of the emulsion. Therefore, Figure 8 shows the viscosity stability profile during storage of all prepared formulations for up to 90 days.
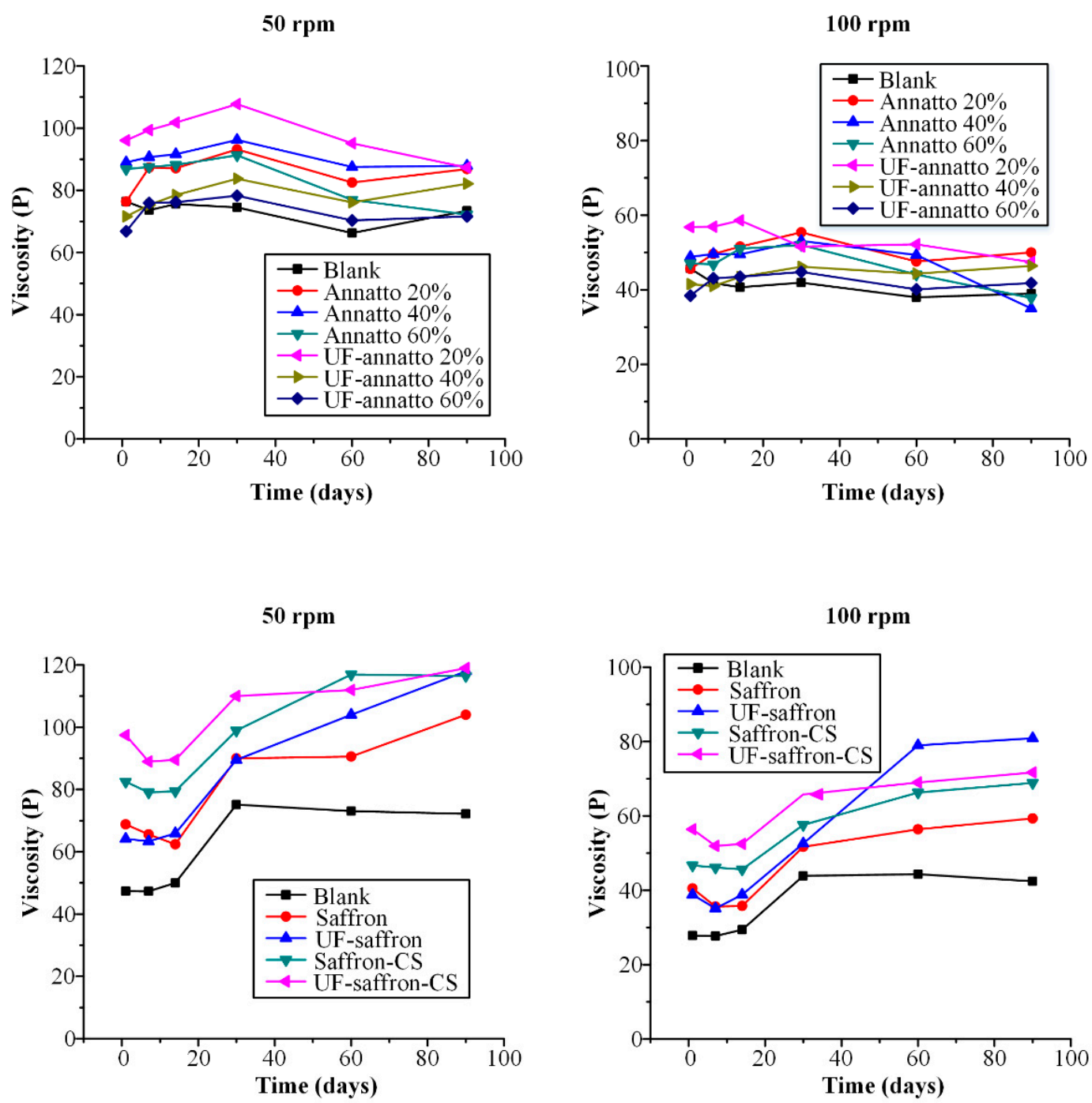

Figure 8. Viscosity profile of prepared sunscreen emulsions during storage stability studies.

In the case of annatto-based sunscreen emulsions, the CS nanoparticles containing 20\% wt. of UF annatto showed the highest viscosity in either 50 or $100 \mathrm{rpms}$. In general, most of the prepared emulsions showed increased viscosity during stability, which may be attributed to the presence of both annatto (or UF annatto) and CS. This is a desirable characteristic of sunscreen formulations since higher viscosity values can result in better photoprotection efficacy, as the consumer usually tends to apply a thicker layer of the product, culminating in a more effective film (higher SPF) [57]. Analytically, in the case of $50 \mathrm{rpms}$, all annatto and UF-annatto-CS nanoparticle emulsions showed an increase (less than $10 \%$ ) in viscosity up to 30 days, and then a small decrease was observed up to 90 days (again less than $10 \%$ from the initial value), indicating that the prepared formulations show good stability in terms of stability. Similar results were observed in the case of $100 \mathrm{rpm}$, except in the case of $40 \%$ and $60 \%$ wt. annatto-CS nanoparticle emulsion, where a higher than $10 \%$ decrease in viscosity was observed after 90 days of storage. This is a common behavior of sunscreens containing a higher percentage of sunscreen agent added in the form of powder, which leads in flocculation of the emulsion [58].

In the case of saffron- and UF-saffron-based sunscreen emulsions, results showed a clear increase in viscosity compared to the blank emulsions in both 50 and $100 \mathrm{rpm}$. Additionally, the use of 
CS-loaded nanoparticles resulted in higher viscosities compared to emulsions containing neat saffron or UF saffron, indicating that the prepared nanoparticles led to a further increase in the emulsion's viscosity. As in the case of annatto-based emulsions, the UF-processed saffron showed the highest initial viscosity in both 50 and $100 \mathrm{rpm}$. All saffron- and UF-saffron-prepared emulsions showed a small decrease in viscosity for up to 14 days followed by a sharp increase in 30 days, while in the case of $50 \mathrm{rpm}$, neat saffron and UF saffron emulsion viscosities increase constantly up to 90 days, indicating that the incorporation of the sunscreen agents within the CS nanoparticle system results in improved rheological stability. Similar results were observed in $100 \mathrm{rpm}$, where the neat UF saffron emulsion showed a $\sim 100 \%$ increase in viscosity after 90 days of storage, compared to the UF-saffron-CS nanoparticle emulsion, where the increase in viscosity was less than $10 \%$.

The stability of the prepared emulsions was also assessed using the freeze at $-4{ }^{\circ} \mathrm{C}$ and defreeze at $25^{\circ} \mathrm{C}$ test, which is a common test in order to simulate the long-term shelf-life stability. Results showed that no phase separation occurred during these stability tests, while no significant viscosity changes were recorded (data not shown). Hence, it can be concluded that the prepared emulsions have excellent long-term shelf-life stability, while their characteristics are unaffected by temperature variations.

Additionally, color stability of the prepared emulsions was assessed over a period of 90 days using reflectance colorimetry. Results in Table 2 show no signs of color change, confirmed by the very close lightness $(\mathrm{L})$, redness $\left(\mathrm{a}^{*}\right)$, and yellowness $\left(\mathrm{b}^{*}\right)$ values of the emulsions.

Table 2. Chromatic co-ordinate values of lightness $(\mathrm{L})$, redness $\left(\mathrm{a}^{*}\right)$, and yellowness $\left(\mathrm{b}^{*}\right)$ for the emulsions of saffron and annatto.

\begin{tabular}{ccccccc}
\hline & \multicolumn{2}{c}{ L } & \multicolumn{2}{c}{$\mathbf{a}^{*}$} & \multicolumn{2}{c}{$\mathbf{b}^{*}$} \\
\cline { 2 - 7 } & Day 1 & Day 90 & Day 1 & Day 90 & Day 1 & Day 90 \\
\hline CS-Saffron & 89.58 & 89.17 & -0.34 & -0.37 & 2.77 & 2.68 \\
CS-UF-Saffron & 88.15 & 88.51 & -0.39 & -0.41 & 2.64 & 2.69 \\
CS-Annatto & 90.01 & 89.95 & -0.40 & -0.44 & 2.51 & 2.46 \\
CS-UF-Annatto & 91.11 & 91.18 & -0.42 & -0.45 & 2.49 & 2.51 \\
\hline
\end{tabular}

\subsubsection{Emulsion SPF}

The efficacy of the prepared sunscreen emulsions in regards to UV radiation protection properties was expressed by the SPF value. Generally, sunscreen products with SPF values of 2-12 provide minimum sunscreen protection, SPF of 12-30 provides moderate protection, while products with SPF $>30$ provide high protection. Table 3 shows the calculated SPF values for the prepared sunscreens along with the blank emulsion. SPF values of all products containing a sunscreen agent varied from 2.15 to 4.85 , indicating that in all cases, a minimum sunscreen protection is achieved compared to blank emulsion $(\mathrm{SPF}=1.00)$. In regards to annatto- or UF-annatto-based emulsions, increasing sunscreen agent concentration did not result in any increase against UV radiation protection (expressed in terms of SPF values), while in the case of saffron and UF saffron, the use of UF saffron resulted in doubled SPF values, indicating that the purification process of saffron resulted in emulsions with improved sunscreen protection.

The increased sunscreen protection conferred by annatto and saffron can be attributed to the presence of a number of ethylene double bonds in their structures which can absorb UV radiation in the same way as a typical synthetic fluorescent brightening agent, e.g., stilbene derivative, does. 
Table 3. Sun protection factor (SPF) values of the prepared emulsions.

\begin{tabular}{cc}
\hline Sample & SPF Value \\
\hline Blank & 1.00 \\
Annatto-CS & \\
$20 \mathrm{wt} \%$ & 2.63 \\
$40 \mathrm{wt} \%$ & 2.27 \\
$60 \mathrm{wt} \%$ & 2.24 \\
UF-annatto-CS & \\
$20 \mathrm{wt} \%$ & 2.76 \\
$40 \mathrm{wt} \%$ & 2.71 \\
$60 \mathrm{wt} \%$ & 2.56 \\
Saffron-CS & 2.15 \\
UF-saffron-CS & 4.85 \\
\hline
\end{tabular}

\section{Materials and Methods}

\subsection{Materials}

For the preparation of nanoparticles, CS with high molecular weight $\left(\mathrm{M}_{\mathrm{W}}: 350,000 \mathrm{~g} / \mathrm{moL}\right.$, deacetylation degree $>75 \%$, and viscosity 800-2000 cps), poly(L-lactide) (PLA) with viscosity $\sim 1.0 \mathrm{dL} / \mathrm{g}$ $(\mathrm{Mn}=59,000 \mathrm{~g} / \mathrm{mol})$, and sodium triphosphate (TPP) were supplied by Aldrich chemicals. Annatto and UF annatto in powder form were received from Alps Industries Ltd. (Tronica City, Ghaziabad, Uttar Pradesh 201102, India), while saffron was received from Crocos Cooperation of Kozani (Kozani, Greece). For the preparation of sunscreen emulsion, olive oil, sesame oil, ethylhexylglycerin, shea butter, glycerin, cetostearyl alcohol, cetyl alcohol, sodium citrate, beeswax, xanthan gum, polysorbate 60, steatic acid, triglycerides, and phenoxyethanol were kindly donated from Novita Group (Thessaloniki, Greece). All other materials and reagents used in this study were of analytical grade of purity.

\subsection{Extraction and Ultrafiltration of Saffron}

For the extraction of saffron, Crocos was placed into a beaker with deionized water $(2 \% w / v)$ and warmed up for almost $3 \mathrm{~h}$ at $80-90{ }^{\circ} \mathrm{C}$ with simultaneous stirring. The resultant suspension was kept until next morning at room temperature in the dark in order to have a complete extraction. The aqueous phase was selected and dried until the dry ground saffron was obtained. For the UF process, a laboratory ultrafiltration unit equipped with a tubular membrane supplied by PCI Membranes (Fareham, Hampshire, UK) was used throughout our work. The membrane used for the UF process was the ES404, a polyethersulphone type membrane supplied by PCI Membranes (UK). The ultrafiltration process for $1.8 \mathrm{~L}$ of a liquid extract $(2 \%)$ of saffron was carried out at $\sim 35^{\circ} \mathrm{C}$ and 10 bar pressure. At the stage of diafiltration, $1.5 \mathrm{~L}$ of water (in portions of $250 \mathrm{~mL}$ ) was added and the process was continued until the concentration of the initial volume was at $\sim 750 \mathrm{~mL}$. The permeate was dried and purified UF saffron was received.

\subsection{Preparation of CS Nanoparticles}

CS nanoparticles were prepared according to the ionotropic gelation method [59]. Blank nanoparticles were obtained upon the addition of TPP aqueous solution to a CS acetic acid solution at a CS-to-TPP ratio of 2:1. The formation of nanoparticles was a result, as previously reported [60], from the interaction between the negative groups of TPP and the positively charged amino groups of CS. For the preparation of annatto or saffron-loaded nanoparticles, an aqueous solution of the substances was added to the prepared CS solution. Three different annatto and UF annatto (i.e., $20 \%, 40 \%$, and $60 \% w / w$ ) and one for saffron and UF saffron (i.e., $33 \% w / w)$ concentrations were tested based on CS quantity. Ultracentrifugation was applied at 13,000 rpm for 10 min in order to collect the nanoparticles, which were then purified twice with deionized water. The purified 
nanoparticles were then frozen and lyophilized using a freeze dryer system (Scanvac Coolsafe, Labogen Scandinavia, Blegistrasse, Baar, Switzerland) for 4 days at about $-100{ }^{\circ} \mathrm{C}$ under vacuum in order to obtain the final dried nanoparticle product.

\subsection{Characterization of CS Nanoparticles}

\subsubsection{Morphological Characterization of Nanoparticles}

The morphology of the prepared nanoparticles was studied using scanning electron microscopy (SEM) (JEOL JSM 6390 and JSM 840A apparatus (Oxford Instruments, Tubney Woods Abingdon, Oxfordshire, UK). The samples were covered with a carbon coating in order to provide good conductivity for the electron beam. Operating conditions were: Accelerating voltage $20 \mathrm{kV}$, probe current $75 \mathrm{nA}$, and counting time $60 \mathrm{~s}$.

\subsubsection{Size Measurements of Nanoparticles}

The particle size distribution of prepared nanoparticles was determined by dynamic light scattering (DLS) using a Zetasizer Nano Instrument (Malvern Instruments, Nano ZS, ZEN3600, Malvern, UK) operating with a 532-nm laser. A suitable amount of nanoparticles was dispersed in distilled water, creating a total concentration $1 \% v / v$ and was kept at $37{ }^{\circ} \mathrm{C}$ under agitation at $100 \mathrm{rpm}$.

\subsubsection{Wide Angle X-ray Diffractometry (WAXD)}

WAXD was used to investigate the physical form (crystalline or amorphous) of drug dispersion within the CS matrix of the nanoparticles. The WAXD experiments were performed from 5 to $60^{\circ}$ using a MiniFlex II XRD system from Rigaku Co. (Chalgrove, Oxford, UK) with Cu Ka radiation $(1=0.154 \mathrm{~nm})$.

\subsubsection{Fourier Transformation Infrared Spectroscopy (FTIR)}

FTIR spectra were obtained using a Perkin-Elmer FTIR spectrometer (model Spectrum 1000, Dresden, Germany). In order to collect the spectra, a small amount of freeze-dried nanoparticles was mixed with $\mathrm{KBr}$ (1 wt\% nanoparticles) and compressed to form tablets. The IR spectra of these tablets, in absorbance mode, were obtained in the spectral region of $450-4000 \mathrm{~cm}^{-1}$ using a resolution of $4 \mathrm{~cm}^{-1}$ and 20 coadded scans.

\subsubsection{Thermogravimetric Analysis (TGA)}

Thermogravimetric analysis (TGA) of neat and encapsulated samples were carried out using an SETARAM SETSYS TG-DTA 16/18 instrument (Lyon, France) by heating the samples from 25 to $600{ }^{\circ} \mathrm{C}$ in a $50 \mathrm{~mL} / \mathrm{min}$ flow of $\mathrm{N}_{2}$ at a heating rate of $20^{\circ} \mathrm{C} / \mathrm{min}$.

\subsubsection{Evaluation of Additive Encapsulation}

The non-entrapped annatto quantity (free annatto) was measured in the clear supernatant collected after nanoparticle centrifugation $\left(20,000 \mathrm{rpm}\right.$ for $30 \mathrm{~min}$ at $\left.25^{\circ} \mathrm{C}\right)$ using UV spectrometry (Shimadzu PharmaSpec UV-1700, Tokyo, Japan) at $400 \mathrm{~nm}$. The corresponding calibration curves were produced using the supernatant of blank nanoparticles. Nanoparticle yield, annatto loading, and entrapment efficiency (EE) were calculated from these equations, respectively:

$$
\begin{aligned}
& \text { Yield }(\%)=(\text { nanoparticle weight }) \times 100 /(\text { weight of polymer and annatto initially }) \\
& \text { Loading }(\%)=(\text { annatto weight in nanoparticles }) \times 100 /(\text { weight of nanoparticles }) \\
& \text { EE }(\%)=(\text { annatto weight in nanoparticles }) \times 100 /(\text { weight of annatto })
\end{aligned}
$$


Nanoparticle weight was estimated after freeze drying of centrifuged nanoparticles.

\subsubsection{In Vitro Cytotoxicity Study}

The cytotoxicity of neat and encapsulated materials, in comparison to PLA, was evaluated by measuring the viability of HUVE cells in the presence of different concentrations of studied materials. Cell viability was determined by the [3-(4,5-dimethylthiazol-2-yl)-2,5-diphenyl tetrazolium bromide] (MTT) assay. HUVEC were seeded in 24-well plates at a density of 30,000 cells per well in $500 \mu \mathrm{L}$ cell culture medium. Twenty-four hours after plating, different amounts of studied materials (suspended in culture medium) were added in the wells. After $24 \mathrm{~h}$ of incubation at $37^{\circ} \mathrm{C}, 50 \mu \mathrm{L}$ of MTT solution $\left(5 \mathrm{mg} / \mathrm{mL}\right.$ in PBS pH 7.4) was added into each well and plates were incubated at $37^{\circ} \mathrm{C}$ for $2 \mathrm{~h}$. The medium was withdrawn and $200 \mu \mathrm{L}$ acidified isopropanol $(0.33 \mathrm{~mL} \mathrm{HCl}$ in $100 \mathrm{~mL}$ isopropanol) was added in each well and agitated thoroughly to dissolve the formed crystals. The solution was transferred to 96-well plates and immediately read on a microplate reader (Biorad, Hercules, CA, USA) at a wavelength of $490 \mathrm{~nm}$. The experiments were performed in triplicate. For each material, five different concentrations were tested, namely, 100, 200, 400, 800, and $1000 \mathrm{mg} / \mathrm{mL}$. The biocompatibility of studied materials was expressed as \% cell viability, which was calculated from the ratio between the number of cells treated with the tested formulations and that of nontreated cells (control).

\subsection{Preparation of Emulsions}

$\mathrm{O} / \mathrm{W}$ emulsions were prepared containing $0.2 \% w / v$ of annatto (or UF annatto)- or saffron (or UF saffron)-loaded CS nanoparticles. Briefly, annatto-loaded CS nanoparticles were homogenized in the water phase, which consisted of glycerin $(4.7 \% w / w)$, xanthan gum $(1.3 \% w / v)$, and citric acid $(0.7 \% w / v)$ heated at $80{ }^{\circ} \mathrm{C}$ and homogenized with the oil phase, which consisted of olive oil $(47.8 \% w / w)$ in the case of annatto and sesame oil $(47.8 \% w / w)$ in the case of saffron, along with cetyl alcohol $(8.7 \% w / w)$, cetostearyl alcohol $(8.7 \% w / w)$, polysorbate $60(8.7 \% w / w)$, shea butter $(8.7 \% w / w)$, steatic acid $(8.7 \% w / w)$, and beeswax $(8.7 \% w / w)$. The resultant emulsions were left under stirring for approximately $2 \mathrm{~h}$ and then phenoxyethanol and ethylhexylglycerin were added.

\subsection{Characterization of Emulsions}

\subsubsection{Emulsion Stability}

The stability of the resultant emulsion was monitored in terms of $\mathrm{pH}$ and viscosity after 7, 14, 30, 60 , and 90 days of storage after preparation. $\mathrm{pH}$ measurements were conducted by dipping the $\mathrm{pH}$ sensor of a Microprocessor WTW pH 535 into the emulsion, while viscosity was measured at 50 and $100 \mathrm{rpm}$ using the R3 spindle of a Visco Star Plus viscometer.

Additionally, freeze-thaw cycle testing study was conducted in order to evaluate the thermal stability of the prepared emulsions. The emulsions were put in the fridge at $-4{ }^{\circ} \mathrm{C}$ for $24 \mathrm{~h}$ and then were removed from the fridge and conditioned at room temperature $\left(25^{\circ} \mathrm{C}\right)$ for $24 \mathrm{~h}$. The above cycle was repeated five times. The emulsions were assessed visually in order to evaluate if any separation effects occurred, while viscosity measurements were also conducted.

Finally, the color stability of the prepared emulsions was assessed over a period of 90 days using reflectance colorimetry. Measurements were performed using a Macbeth CE 3000 spectrophotometer (Macbeth, London, UK) under D65 illumination, 10 degrees standard observer with UV included and specular component excluded. The lightness $(\mathrm{L})$, redness $\left(\mathrm{a}^{*}\right)$, and yellowness $\left(\mathrm{b}^{*}\right)$ values of the emulsions were measured in order to assess the color stability of the emulsions.

\subsubsection{SPF Determination}

SPF was determined using the diluted solution transmittance method. Briefly, all samples were weighed $(1 \mathrm{~g})$, transferred to a $100-\mathrm{mL}$ volumetric flask, diluted to volume with ethanol, mixed for $5 \mathrm{~min}$, and then filtered through Whatman filters. A 5-mL sample was transferred to a 25-mL 
volumetric flask and diluted to volume with ethanol. The absorption values were obtained in the range of 290-320 nm (every $5 \mathrm{~nm}$ ) and three determinations were made at each point. Then, the Mansur equation was used to determine the SPF values of the formulations:

$$
\mathrm{SPF}=\mathrm{CF} \times \sum_{320}^{290} \mathrm{EE}(\lambda) \times \mathrm{I}(\lambda) \times \operatorname{abs}(\lambda)
$$

where $\mathrm{CF}=10$ (correction factor), EE $(\lambda)=$ erythemogenic effect of radiation at wavelength $\lambda, I(\lambda)=$ intensity of solar light at wavelength $\lambda$, and $\operatorname{abs}(\lambda)=$ absorbance of sample at wavelength $\lambda$. The values for the term "EE $\times$ I" are constants, which were determined by Sayre et al. [61].

\section{Conclusions}

CS-based nanoparticles were prepared with all tested sunscreen agents (annatto, UF annatto, saffron, and UF saffron). SEM analysis revealed that formed nanoparticles had a spherical and irregular shape, while their size varied from $\sim 150$ to $\sim 500 \mathrm{~nm}$. Additionally, XRD analysis showed amorphous dispersion in the case of annatto and UF annatto and crystalline dispersion in the case of saffron and UF saffron nanoparticles, while FTIR analysis showed the formation of H-bond interactions. Sunscreen emulsions prepared from the resultant CS-sunscreen agent(s) nanoparticles showed good storage stability for up to 90 days at room temperature in terms of $\mathrm{pH}$ and viscosity, while minimum sunscreen protection was determined with SPF values varying from 2.15 to 4.85 in all cases. All materials have high color stability as well as low cytotoxicity.

Author Contributions: S.N. and V.G. synthesized all novel compounds. E.C. and S.N. run the characterization of prepared nanoparticles, S.L. and P.N. prepared emulsions, L.M. characterized the emulsions, P.B., N.N, and D.N.B. organized the experiments and wrote the paper.

Funding: This research received no external funding. Article Processing Charge was sponsored by MDPI.

Conflicts of Interest: The authors declare no conflict of interest.

\section{References}

1. Cadet, J.; Douki, T.; Ravanat, J.L. Oxidatively generated damage to cellular DNA by UVB and UVA radiation. Photochem. Photobiol. 2015, 91, 140-155. [CrossRef] [PubMed]

2. Agbai, O.N.; Buster, K.; Sanchez, M.; Hernandez, C.; Kundu, R.V.; Chiu, M.; Roberts, W.E.; Draelos, Z.D.; Bhushan, R.; Taylor, S.C.; et al. Skin cancer and photoprotection in people of color: A review and recommendations for physicians and the public. J. Am. Acad. Dermatol. 2014, 70, 748-762. [CrossRef] [PubMed]

3. Shetty, P.K.; Venuvanka, V.; Jagani, H.V.; Chethan, G.H.; Ligade, V.S.; Musmade, P.B.; Nayak, U.Y.; Reddy, M.S.; Kalthur, G.; Udupa, N.; et al. Development and evaluation of sunscreen creams containing morin-encapsulated nanoparticles for enhanced UV radiation protection and antioxidant activity. Int. J. Nanomed. 2015, 10, 6477-6491.

4. Serpone, N.; Dondi, D.; Albini, A. Inorganic and organic UV filters: Their role and efficacy in sunscreens and suncare products. Inorg. Chim. Acta 2007, 360, 794-802. [CrossRef]

5. Sarkany, R. Sun protection strategies. Medicine 2017, 45, 444-447. [CrossRef]

6. Maske, P.P.; Lokapure, S.G.; Nimbalkar, D.; Malavi, S.; D'Souza, J.I. In vitro determination of sun protection factor and chemical stability of Rosa kordesii extract gel. J. Pharm. Res. 2013, 7, 520-524. [CrossRef]

7. Binks, B.P.; Fletcher, P.D.I.; Johnson, A.J.; Marinopoulos, I.; Crowther, J.; Thompson, M.A. How the sun protection factor (SPF) of sunscreen films change during solar irradiation. J. Photochem. Photobiol. A Chem. 2017, 333, 186-199. [CrossRef]

8. Lin, C.-C.; Lin, W.-J. Sun Protection Factor Analysis of Sunscreens Containing Titanium Dioxide Nanoparticles. J. Food Drug Anal. 2011, 19, 1-8.

9. Newman, M.D.; Stotland, M.; Ellis, J.I. The safety of nanosized particles in titanium dioxide- and zinc oxide-based sunscreens. J. Am. Acad. Dermatol. 2009, 61, 685-692. [CrossRef] [PubMed]

10. AbdElhady, M.M. Preparation and Characterization of Chitosan/Zinc Oxide Nanoparticles for Imparting Antimicrobial and UV Protection to Cotton Fabric. Int. J. Carbohydr. Chem. 2012, 2012, 6. [CrossRef] 
11. Chung, K.-H.; Jung, H.-Y.; Lee, Y.-W.; Lee, K.-Y. Preparation of $\mathrm{TiO}_{2}$-loaded nanocapsules and their sun protection behaviors. J. Ind. Eng. Chem. 2010, 16, 261-266. [CrossRef]

12. Hirano, S.; Noishiki, Y. The blood compatibility of chitosan and N-acylchitosans. J. Biomed. Mater. Res. 1985, 19, 413-417. [CrossRef] [PubMed]

13. Koukaras, E.N.; Papadimitriou, S.A.; Bikiaris, D.N.; Froudakis, G.E. Insight on the Formation of Chitosan Nanoparticles through Ionotropic Gelation with Tripolyphosphate. Mol. Pharm. 2012, 9, 2856-2862. [CrossRef] [PubMed]

14. Papadimitriou, S.; Bikiaris, D.; Avgoustakis, K.; Karavas, E.; Georgarakis, M. Chitosan nanoparticles loaded with dorzolamide and pramipexole. Carbohydr. Polym. 2008, 73, 44-54. [CrossRef]

15. Archana, D.; Dutta, J.; Dutta, P.K. Evaluation of chitosan nano dressing for wound healing: Characterization, in vitro and in vivo studies. Int. J. Biol. Macromol. 2013, 57, 193-203. [CrossRef] [PubMed]

16. Jayakumar, R.; Prabaharan, M.; Sudheesh Kumar, P.T.; Nair, S.V.; Tamura, H. Biomaterials based on chitin and chitosan in wound dressing applications. Biotechnol. Adv. 2011, 29, 322-337. [CrossRef] [PubMed]

17. Kumar, P.T.; Lakshmanan, V.K.; Anilkumar, T.V.; Ramya, C.; Reshmi, P.; Unnikrishnan, A.G.; Nair, S.V.; Jayakumar, R. Flexible and microporous chitosan hydrogel/nano ZnO composite bandages for wound dressing: In vitro and in vivo evaluation. ACS Appl. Mater. Interfaces 2012, 4, 2618-2629. [CrossRef] [PubMed]

18. Madihally, S.V.; Matthew, H.W. Porous chitosan scaffolds for tissue engineering. Biomaterials 1999, 20, 1133-1142. [CrossRef]

19. Ravi Kumar, M.N.V. A review of chitin and chitosan applications. React. Funct. Polym. 2000, 46, 1-27. [CrossRef]

20. Kean, T.; Thanou, M. Biodegradation, biodistribution and toxicity of chitosan. Adv. Drug Deliv. Rev. 2010, 62, 3-11. [CrossRef] [PubMed]

21. Chen, M.-C.; Mi, F.-L.; Liao, Z.-X.; Hsiao, C.-W.; Sonaje, K.; Chung, M.-F.; Hsu, L.-W.; Sung, H.-W. Recent advances in chitosan-based nanoparticles for oral delivery of macromolecules. Adv. Drug Deliv. Rev. 2013, 65, 865-879. [CrossRef] [PubMed]

22. Casettari, L.; Illum, L. Chitosan in nasal delivery systems for therapeutic drugs. J. Control. Release 2014, 190, 189-200. [CrossRef] [PubMed]

23. Aungst, B.J. Absorption Enhancers: Applications and Advances. AAPS J. 2012, 14, 10-18. [CrossRef] [PubMed]

24. Koutroumanis, K.P.; Avgoustakis, K.; Bikiaris, D. Synthesis of cross-linked N-(2-carboxybenzyl)chitosan $\mathrm{pH}$ sensitive polyelectrolyte and its use for drug controlled delivery. Carbohydr. Polym. 2010, 82, 181-188. [CrossRef]

25. Nanaki, S.; Tseklima, M.; Christodoulou, E.; Triantafyllidis, K.; Kostoglou, M.; Bikiaris, D. Thiolated Chitosan Masked Polymeric Microspheres with Incorporated Mesocellular Silica Foam (MCF) for Intranasal Delivery of Paliperidone. Polymers 2017, 9, 617. [CrossRef]

26. Nanaki, S.G.; Koutsidis, I.A.; Koutri, I.; Karavas, E.; Bikiaris, D. Miscibility study of chitosan/2-hydroxyethyl starch blends and evaluation of their effectiveness as drug sustained release hydrogels. Carbohydr. Polym. 2012, 87, 1286-1294. [CrossRef]

27. Siafaka, P.I.; Titopoulou, A.; Koukaras, E.N.; Kostoglou, M.; Koutris, E.; Karavas, E.; Bikiaris, D.N. Chitosan derivatives as effective nanocarriers for ocular release of timolol drug. Int. J. Pharm. 2015, 495, 249-264. [CrossRef] [PubMed]

28. Nagpal, K.; Singh, S.K.; Mishra, D.N. Chitosan nanoparticles: A promising system in novel drug delivery. Chem. Pharm. Bull. 2010, 58, 1423-1430. [CrossRef] [PubMed]

29. Prabaharan, M. Chitosan-based nanoparticles for tumor-targeted drug delivery. Int. J. Biol. Macromol. 2015, 72, 1313-1322. [CrossRef] [PubMed]

30. Wang, J.J.; Zeng, Z.W.; Xiao, R.Z.; Xie, T.; Zhou, G.L.; Zhan, X.R.; Wang, S.L. Recent advances of chitosan nanoparticles as drug carriers. Int. J. Nanomed. 2011, 6, 765-774.

31. Panos, I.; Acosta, N.; Heras, A. New drug delivery systems based on chitosan. Curr. Drug Discov. Technol. 2008, 5, 333-341. [CrossRef] [PubMed]

32. Koukaras, E.N.; Papadimitriou, S.A.; Bikiaris, D.N.; Froudakis, G.E. Properties and energetics for design and characterization of chitosan nanoparticles used for drug encapsulation. RSC Adv. 2014, 4, 12653-12661. [CrossRef] 
33. Zastrow, L.; Meinke, M.C.; Albrecht, S.; Patzelt, A.; Lademann, J. From UV Protection to Protection in the Whole Spectral Range of the Solar Radiation: New Aspects of Sunscreen Development. In Ultraviolet Light in Human Health, Diseases and Environment; Ahmad, S.I., Ed.; Springer International Publishing: Cham, Switzerland, 2017; pp. 311-318.

34. Meinke, M.C.; Syring, F.; Schanzer, S.; Haag, S.F.; Graf, R.; Loch, M.; Gersonde, I.; Groth, N.; Pflucker, F.; Lademann, J. Radical protection by differently composed creams in the UV/VIS and IR spectral ranges. Photochem. Photobiol. 2013, 89, 1079-1084. [CrossRef] [PubMed]

35. Lademann, J.; Schanzer, S.; Jacobi, U.; Schaefer, H.; Pflucker, F.; Driller, H.; Beck, J.; Meinke, M.; Roggan, A.; Sterry, W. Synergy effects between organic and inorganic UV filters in sunscreens. J. Biomed. Opt. 2005, 10, 014008. [CrossRef] [PubMed]

36. Syring, F.; Weigmann, H.J.; Schanzer, S.; Meinke, M.C.; Knorr, F.; Lademann, J. Investigation of Model Sunscreen Formulations Comparing the Sun Protection Factor, the Universal Sun Protection Factor and the Radical Formation Ratio. Skin Pharmacol. Physiol. 2016, 29, 18-23. [CrossRef] [PubMed]

37. Nichols, J.A.; Katiyar, S.K. Skin photoprotection by natural polyphenols: Anti-inflammatory, antioxidant and DNA repair mechanisms. Arch. Dermatol. Res. 2010, 302, 71-83. [CrossRef] [PubMed]

38. Andreo-Filho, N.; Bim, A.V.K.; Kaneko, T.M.; Kitice, N.A.; Haridass, I.N.; Abd, E.; Santos Lopes, P.; Thakur, S.S.; Parekh, H.S.; Roberts, M.S.; et al. Development and Evaluation of Lipid Nanoparticles Containing Natural Botanical Oil for Sun Protection: Characterization and in vitro and in vivo Human Skin Permeation and Toxicity. Skin Pharmacol. Physiol. 2018, 31, 1-9. [CrossRef] [PubMed]

39. Sri Vidhya, M.; Bhanu Rekha, V. Effect of Knitted Bamboo Structures Dyed With Natural Colorants on Ultraviolet Radiation Protection. J. Text. Sci. Eng. 2012, 2, 2-4.

40. Morrison, E.Y.; Thompson, H.; Pascoe, K.; West, M.; Fletcher, C. Extraction of an hyperglycaemic principle from the annatto (Bixa orellana), a medicinal plant in the West Indies. Trop. Geogr. Med. 1991, 43, 184-188. [PubMed]

41. Mashmoul, M.; Azlan, A.; Khaza'ai, H.; Mohd Yusof, B.N.; Mohd Noor, S. Saffron: A Natural Potent Antioxidant as a Promising Anti-Obesity Drug. Antioxidants 2013, 2, 293-308. [CrossRef] [PubMed]

42. Nair, S.C.; Pannikar, B.; Panikkar, K.R. Antitumour activity of saffron (Crocus sativus). Cancer Lett. 1991, 57, 109-114. [CrossRef]

43. Ríos, J.L.; Recio, M.C.; Giner, R.M.; Máñez, S. An Update Review of Saffron and its Active Constituents. Phytother. Res. 1996, 10, 189-193. [CrossRef]

44. Hosseinzadeh, H.; Modaghegh, M.H.; Saffari, Z. Crocus Sativus L. (Saffron) Extract and its Active Constituents (Crocin and Safranal) on Ischemia-Reperfusion in Rat Skeletal Muscle. Evid.-Based Complement. Altern. Med. 2009, 6, 343-350. [CrossRef] [PubMed]

45. Hosseinzadeh, H.; Younesi, H.M. Antinociceptive and anti-inflammatory effects of Crocus sativus L. stigma and petal extracts in mice. BMC Pharmacol. 2002, 2,7.

46. Chattopadhyay, S.N.; Pan, N.C.; Roy, A.K.; Saxena, S.; Khan, A. Development of natural dyed jute fabric with improved colour yield and UV protection characteristics. J. Text. Inst. 2013, 104, 808-818. [CrossRef]

47. Golmohammadzadeh, S.; Jaafari, M.R.; Hosseinzadeh, H. Does Saffron Have Antisolar and Moisturizing Effects? Iran. J. Pharm. Res. 2010, 9, 133-140. [PubMed]

48. Ing, L.Y.; Zin, N.M.; Sarwar, A.; Katas, H. Antifungal activity of chitosan nanoparticles and correlation with their physical properties. Int. J. Biomater. 2012, 2012, 632698. [CrossRef] [PubMed]

49. Lee, F.Y.; Htar, T.T.; Akowuah, G.A. ATR-FTIR and Spectrometric Methods for the Assay of Crocin in Commercial Saffron Spices (Crocus savitus L.). Int. J. Food Prop. 2015, 18, 1773-1783. [CrossRef]

50. Ioelovich, M. Crystallinity and Hydrophility of Chitin and Chitosan. J. Chem. 2014, 3, 7-14.

51. Chrissafis, K.; Paraskevopoulos, K.M.; Papageorgiou, G.Z.; Bikiaris, D.N. Thermal and dynamic mechanical behavior of bionanocomposites: Fumed silica nanoparticles dispersed in poly(vinyl pyrrolidone), chitosan, and poly(vinyl alcohol). J. Appl. Polym. Sci. 2008, 110, 1739-1749. [CrossRef]

52. Karavelidis, V.; Giliopoulos, D.; Karavas, E.; Bikiaris, D. Nanoencapsulation of a water soluble drug in biocompatible polyesters. Effect of polyesters melting point and glass transition temperature on drug release behavior. Eur. J. Pharm. Sci. 2010, 41, 636-643. [CrossRef] [PubMed]

53. Karavelidis, V.; Karavas, E.; Giliopoulos, D.; Papadimitriou, S.; Bikiaris, D. Evaluating the effects of crystallinity in new biocompatible polyester nanocarriers on drug release behavior. Int. J. Nanomed. 2011, 6, 3021-3032. 
54. Smaoui, S.; Ben Hlima, H.; Ben Chobba, I.; Kadri, A. Development and stability studies of sunscreen cream formulations containing three photo-protective filters. Arab. J. Chem. 2017, 10, S1216-S1222. [CrossRef]

55. Some, I.T.; Bogaerts, P.; Hanus, R.; Hanocq, M.; Dubois, J. Improved kinetic parameter estimation in pH-profile data treatment. Int. J. Pharm. 2000, 198, 39-49. [CrossRef]

56. Matousek, J.L.; Campbell, K.L.; Kakoma, I.; Solter, P.F.; Schaeffer, D.J. Evaluation of the effect of pH on in vitro growth of Malassezia pachydermatis. Can. J. Vet. Res. 2003, 67, 56-59. [PubMed]

57. Nesseem, D. Formulation of sunscreens with enhancement sun protection factor response based on solid lipid nanoparticles. Int. J. Cosmet. Sci. 2011, 33, 70-79. [CrossRef] [PubMed]

58. Nasu, A.; Otsubo, Y. Effects of polymeric dispersants on the rheology and UV-protecting properties of complex suspensions of titanium dioxides and zinc oxides. Colloids Surfaces A Physicochem. Eng. Asp. 2008, 326, 92-97. [CrossRef]

59. Calvo, P.; Vila-Jato, J.L.; Alonso, M.J. Evaluation of cationic polymer-coated nanocapsules as ocular drug carriers. Int. J. Pharm. 1997, 153, 41-50. [CrossRef]

60. Aktas, Y.; Andrieux, K.; Alonso, M.J.; Calvo, P.; Gursoy, R.N.; Couvreur, P.; Capan, Y. Preparation and in vitro evaluation of chitosan nanoparticles containing a caspase inhibitor. Int. J. Pharm. 2005, 298, 378-383. [CrossRef] [PubMed]

61. Sayre, R.M.; Agin, P.P.; LeVee, G.J.; Marlowe, E. A comparison of in vivo and in vitro testing of sunscreening formulas. Photochem. Photobiol. 1979, 29, 559-566. [CrossRef] [PubMed]

Sample Availability: Samples of all studied compounds are available from the authors.

(C) 2018 by the authors. Licensee MDPI, Basel, Switzerland. This article is an open access article distributed under the terms and conditions of the Creative Commons Attribution (CC BY) license (http://creativecommons.org/licenses/by/4.0/). 